\title{
In Vitro Activity of Plazomicin among Carbapenem-resistant Enterobacteriaceae
}

\author{
Sara Essam*iD, Nada Nawar(D), Mohamed ElBashaar(D), May Soliman (i), May Abdelfattah (i) \\ Department of Clinical and Chemical Pathology, Faculty of Medicine, Cairo University, Giza, Egypt
}

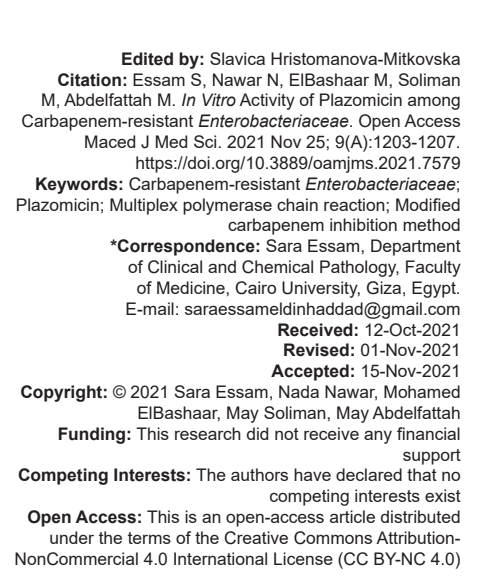

\begin{abstract}
BACKGROUND: Carbapenem-resistant Enterobacteriaceae (CRE) have been disseminated worldwide and became a global threat. Due to limited therapeutic drugs plazomicin - a new semisynthetic aminoglycoside - have been suggested as an alternative option due to its stability against aminoglycosides modifying enzymes.

AIM: This study aims to assess the in vitro activity of plazomicin against CRE isolates and to detect different types of carbapenemases among these isolates.

METHODS: In this study, 102 CRE isolates were collected from different clinical samples at Cairo University hospitals and the presence of carbapenemases was detected by modified carbapenem inhibition method and multiplex polymerase chain reaction tests. Plazomicin susceptibility testing was done using E-test.

RESULTS: The most frequently detected carbapenemase genes were bla $\mathrm{NDM}_{\text {in }} 75(73.5 \%)$ isolates, followed by $b / a_{\mathrm{OXA}-48}$ in $57(55.9 \%)$ and bla $_{\mathrm{KPC}}$ in $16(15.5 \%)$ isolates. Plazomicin was active against $32(31.4 \%)$ isolates. Among the isolates carrying $b / a_{\mathrm{NDM}}$ gene only and those carrying $b / a_{\mathrm{OXA}-48}$ gene only, $21 \%$ and $41 \%$ were sensitive to plazomicin, respectively. Plazomicin showed the highest sensitivity against CRE isolates compared to the other tested antibiotics.

CONCLUSION: Plazomicin might be a good option for treatment of infections caused by CRE. In health-care settings where $b^{\prime} a_{\mathrm{NDM}}$ gene is prevalent, plazomicin may not be a good therapeutic option for CRE infections.
\end{abstract}

\section{Introduction}

Carbapenem-resistant

Enterobacteriaceae (CRE) are resistant to almost all $\beta$-lactams leaving only few and unfortunately older, antimicrobial classes with adequate activity [1]. These limited therapeutic options are highlighting the need for new antibiotics to treat serious infections caused by these resistant pathogens. Since the early 1980s, carbapenems are considered the last line of defense against multidrug-resistant (MDR) Gramnegative organisms [2]. CRE are defined as pathogens that are resistant to at least one carbapenem or are proved to produce a carbapenemase [3]. Over the past two decades, dissemination of CRE has been observed worldwide [4], [5]. Klebsiella pneumoniae (K. pneumoniae) isolates showed the highest rate of carbapenem resistance among Enterobacteriaceae [6], [7].

In Egypt, Kotb et al., 2020, have reported that $1105(47.9 \%)$ of the 2306 Enterobacteriaceae isolates included in the surveillance from 2011 to 2017 were CRE [8]. The highest percentage of CRE was among Klebsiella spp. $53.7 \%$ followed by Enterobacter spp. $43.5 \%$, while a smaller percentage of Escherichia coli (E. coli) isolates $27.1 \%$ were CRE.
Few antibiotics are still active against CRE, since they usually carry resistance genes to $\beta$-lactams, aminoglycosides, and fluoroquinolones. Older antimicrobials such as fosfomycin and polymyxins that were rarely used in the past due to efficacy and toxicity concerns may be considered [9]. Plazomicin is a semisynthetic aminoglycoside that inhibits bacterial protein synthesis. It has an important in vitro activity against MDR Enterobacteriaceae including those producing aminoglycosides modifying enzymes (AMEs), extended spectrum beta-lactamases, and carbapenemases. Enhanced activity of plazomicin against Enterobacteriaceae is due to its stability to commonly encountered AMEs that inhibit the activity of other aminoglycosides [10], [11].

In June 2018, plazomicin was approved by the US Food and Drug Administration (FDA) for treatment of complicated urinary tract infections, including acute pyelonephritis [12] and is waiting for FDA approval for acute bloodstream infections caused by MDR Enterobacteriaceae infections, including CRE [13].

\section{Aim of the study}

In the light of the above, this study aimed at assessing the in vitro activity of plazomicin against CRE 
isolates and to detect different types of carbapenemases among these isolates.

\section{Methods}

This cross-sectional study was performed in Cairo University Hospitals, Clinical Pathology Department. A total of 102 CRE isolates from different clinical specimens were collected without duplication from October 2019 to October 2020. All isolates were collected from cultures sent to the laboratory as a part of the routine medical service provided to the patients and were cultured aerobically on routine blood, chocolate, MacConkey, and CLED agar media at $37^{\circ} \mathrm{C}$ for (24-48) $\mathrm{h}$ and Enterobacteriaceae were further identified by Gram staining and conventional biochemical reactions that include triple sugar iron, lysine iron agar, motility indole ornithine, simmon citrate, and urease agar.

Susceptibility to carbapenems was determined by the standard Kirby-Bauer disk diffusion method to detect CRE isolates according to clinical and laboratory standards institute breakpoints for carbapenems [14]. Bacteriological strains were suspended in $20 \%$ glycerol trypticase soy broth and stored at $-80^{\circ} \mathrm{C}$ for further laboratory testing. Subculture of the stored isolates were done on blood agar and incubated aerobically at $37^{\circ} \mathrm{C}$ for $24 \mathrm{~h}$, then subjected to:

\section{Phenotypic detection of carbapenemase enzymes activity}

Phenotypic detection of carbapenemase enzymes activity was detected by modified carbapenem inactivation method (mCIM) and EDTA-mCIM (eCIM) [15].

\section{Detection of carbapenemase genes by conventional multiplex polymerase chain reaction (PCR)}

DNA extraction, multiplex conventional PCR, and gel electrophoresis according to Poirel et al. [16]. Multiplex conventional PCR was performed to detect the following carbapenemase genes using three different multiplex reactions:

- $\quad$ Reaction 1: OXA-48, NDM, KPC, and BIC

- $\quad$ Reaction 2: AIM, GIM, SIM, and DIM

- $\quad$ Reaction 3: IMP, VIM, and SPM.

\section{Plazomicin susceptibility testing}

Plazomicin susceptibility was determined using minimal inhibitory concentration (MIC) method on Muller-Hinton agar using plazomicin E test (PLZ;
0.016-256 $\mu \mathrm{g} / \mathrm{mL}$ ) (liofilchem diagnostics, Italy) and the MIC value was determined [17].

Quality control measures were performed all through the different tests including the culture media, biochemical reactions, and antimicrobial discs.

- $\quad$ E. coli ATCC 25922 was used for plazomicin susceptibility testing control.

- K. pneumoniae NCTC 13443 was used for PCR technique as a positive control of NDM.

\section{Statistical analysis}

Data were statistically described in terms of range, mean \pm standard deviation $( \pm S D)$, and percentages. A probability value $p<0.05$ was considered statistically significant. All statistical calculations were done using computer programs Microsoft Excel 2010 and Statistical Package for the Social Science version 23 for Microsoft Windows. This study was approved by the ethical committee of faculty of medicine Cairo University.

\section{Results}

During the study period, a total of 10,964 clinical samples were sent to the Clinical Pathology Department of Cairo University Hospitals. Gramnegative pathogens were identified in 3301 (30.1\%) samples. Among the 3301 Gram-negative isolates, 2229 (67.5\%) were Enterobacteriaceae isolates; out of which $131(5.8 \%)$ isolates were CRE, and a total of 102 CRE isolates were randomly collected.

Out of 102 CRE isolates, 97 (95\%) were klebsiella species, while $5(5 \%)$ isolates were other types including E. coli, Proteus, and Citrobacterspecies.

Results of mCIM and eCIM tests are illustrated in Tables 1 and 2, respectively.

Table 1: Results of mCIM test according to CLSI [15]

\begin{tabular}{lll}
\hline Result & Number & Percent \\
\hline Positive $^{\mathrm{a}}$ & 65 & 63.7 \\
Negative $^{\mathrm{b}}$ & 24 & 23.5 \\
Indeterminate $^{\mathrm{c}}$ & 13 & 12.7 \\
Total & 102 & 100 \\
\hline "a": Positive: Interpret eCIM, "b": Negative: Do not interpret eCIM, "c": Indeterminate: The presence or \\
absence of Carbapenemase cannot be confirmed thus do not interpret eCIM. mCIM: Modified carbapenem \\
inactivation method, CLSI: Clinical and Laboratory Standards Institute.
\end{tabular}

Table 2: Results of eCIM test according to CLSI [15]

\begin{tabular}{lll}
\hline Result & Number & Percent \\
\hline MBL positive & 50 & 49 \\
MBL negative & 15 & 14.7 \\
Not applicable & 37 & 36.3 \\
Total & 102 & 100 \\
\hline eCIM: EDTA-modified carbapenem inactivation method, CLSI: Clinical and Laboratory Standards Institute, \\
MBL: Metallo- $\beta$-lactamases.
\end{tabular}

Results of multiplex PCR are illustrated in Table 3.

Plazomicin susceptibility testing have detected that $32(31.4 \%)$ isolates were sensitive as shown in Table 4. 
Table 3: Carbapenemase genes detected by PCR

\begin{tabular}{|c|c|c|c|c|c|}
\hline \multirow{2}{*}{$\begin{array}{l}\text { Carbapenemase class } \\
\text { Class A }\end{array}$} & \multirow{2}{*}{$\begin{array}{l}\text { Carbapenemase gene } \\
\text { bla }_{\mathrm{KPC}}\end{array}$} & \multicolumn{2}{|c|}{$\begin{array}{l}\text { Number } \\
\text { of positive } \\
\text { isolates }\end{array}$} & \multicolumn{2}{|c|}{ Percent } \\
\hline & & 16 & & 15.7 & \\
\hline Class B & $b l a_{\mathrm{NDM}}$ & 75 & 77 & 73.5 & 75.5 \\
\hline & bla & 5 & & 4.9 & \\
\hline & bla $_{\mathrm{vim}}$ & 4 & & 3.9 & \\
\hline & $b l a_{\mathrm{BIC}}$ & 3 & & 2.9 & \\
\hline & $b l a_{\text {SIM }}$ & 3 & & 2.9 & \\
\hline & $b l a_{\text {AIM }}$ & 1 & & 1 & \\
\hline & $b l a_{\text {DIM }}$ & 1 & & 1 & \\
\hline & $b l a_{\mathrm{SPM}}$ & 0 & & 0 & \\
\hline & bla & 0 & & 0 & \\
\hline Class D & bla $a_{\text {OXA }-48}$ & 57 & & 55.9 & \\
\hline
\end{tabular}

Plazomicin susceptibility among isolates carrying bla ${ }_{\mathrm{NDM}}$ or bla ${ }_{\mathrm{OXA}-48}$ gene only is shown in Table 5. Table 4: Susceptibility rate of plazomicin and MIC values among CRE isolates

\begin{tabular}{lllll}
\hline $\begin{array}{l}\text { Susceptibility } \\
\text { pattern }\end{array}$ & MIC $(\mu \mathrm{g} / \mathrm{ml})$ & Number & Total number & Percent \\
\hline Sensitive & 0.25 & 1 & 32 & 31.4 \\
& 0.38 & 12 & & \\
& 0.5 & 10 & & \\
& 0.75 & 2 & & \\
& 1 & 2 & & 1 \\
Intermediate & 1.5 & 5 & 1 & 67.6 \\
Resistant & 6 & 1 & 69 & 100 \\
Total & $>256$ & 69 & 102 & \\
\hline
\end{tabular}

Susceptibility pattern of the 102 CRE isolates to different antibiotics is illustrated in Figure 1.

Table 5: Susceptibility of plazomicin among isolates carrying blaNDM or blaOXA-48 gene only

\begin{tabular}{|c|c|c|c|c|}
\hline Isolates gene group & Sensitive (\%) & Resistant (\%) & Total $(\%)$ & $p$-value \\
\hline Isolates carrying $b / a_{N}$ & $4(21)$ & $15(79)$ & $19(100)$ & 0.19 \\
\hline Isolates carrying bla & $7(41)$ & $10(59)$ & $17(100)$ & \\
\hline
\end{tabular}

Isolates carrying bla $a_{0 \times A-48}$ gene only $7(41)$ $10(59)$ $17(100)$

\section{Discussion}

In this study, the most common isolated pathogen was Klebsiella spp. in $95 \%$ of the isolates. Similarly, other studies reported that Klebsiella spp. was the most common isolated pathogen [18], [19]. In our study, we found that mCIM was positive in $63.7 \%$ of $\mathrm{CRE}$ isolates. Recently, similar results were reported by other studies [20], [21].

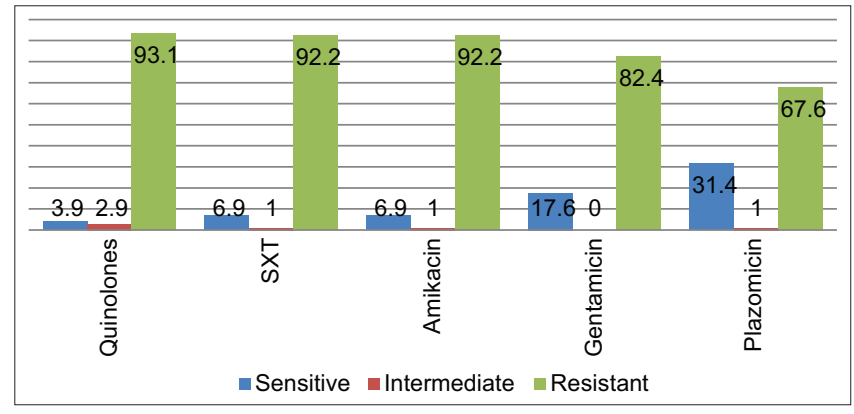

Figure 1: Susceptibility rates of plazomicin and other antibiotics among carbapenem resistant Enterobacteriaceae isolates. SXT: Sulfamethoxazole-trimethoprim

Regarding carbapenemase genes, we found that the most frequently detected gene was bla ${ }_{\mathrm{NDM}}$, followed by bla ${ }_{\mathrm{OXA}-48}$ and bla $_{\mathrm{KPC}}$. Comparable results were reported by a previous study [18]. While, other studies reported that bla oxA-48 $_{1}$ gene was the most prevalent followed by bla ${ }_{\text {OXA-48 }}$ [20], [22]. Although the latter studies had the same geographical distribution as this study, they showed different gene prevalence. This might be explained by the difference in sample size between our study and their as our sample size was almost double the sample size they tested.

In the current study, plazomicin was active against $31.4 \%$ of the isolates. While among the isolates carrying bla ${ }_{\mathrm{NDM}}$ gene only and those carrying bla OXA-48 $_{\text {in }}$ gene only, $21 \%$ and $41 \%$ were sensitive to plazomicin, respectively. Earlier studies reported similar sensitivity rates of plazomicin among bla ${ }_{\mathrm{NDM}}$ carrying isolates. While, higher sensitivity rates were detected among

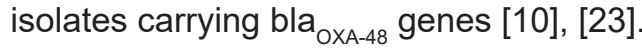

On the other hand, Plazomicin showed the higher sensitivity rates in other studies [24], [25], [26]. The discrepancy between our results and these studies may be related to the different characteristics of the tested isolates, as most of our isolates were carrying bla $_{\text {NDM }}$ genes $73.5 \%$. As previously discussed, bla ${ }_{N D M}$ genes are commonly co-expressed with 16S-RMTases; the main mechanism of resistance to plazomicin [27].

We found also that plazomicin showed the highest susceptibility rate $(31.4 \%)$ among CRE isolates in comparison to the other routinely tested antibiotics (quinolones [3.9\%], sulfamethoxazoletrimethoprim [6.9\%], amikacin [6.9\%], and gentamicin $[17.6 \%])$. Similar findings were reported in various studies [23], [25], [26], [28].

Our study results revealed that the infections caused by CRE represent a serious public health problem even in the presence of new antibiotics like plazomicin.

\section{Limitations of the study}

Detection of plazomicin resistance mechanism in plazomicin-resistant isolates was not performed. Larger sample size is recommended for more accurate evaluation of plazomicin activity.

\section{Conclusion}

Further efforts should be exerted toward the control of spread of Klebsiella spp. infections being the most commonly isolated. In addition, more studies should be directed to CRE isolates carrying bla ${ }_{\mathrm{NDM}}$, $b / a_{\mathrm{OXA}-48}$, and $b / a_{\mathrm{KPC}}$, respectively. Although plazomicin showed the highest sensitivity against CRE isolates compared to the other tested antibiotics thus it might be a good option for treatment of infections caused 
by $\mathrm{CRE}$, in health-care settings where $b / a_{\mathrm{NDM}}$ gene is prevalent, it may not be a good therapeutic option for CRE infections.

\section{Recommendations}

Our study results recommend further studies with larger sample size to evaluate plazomicin activity against different species of MDR bacteria including CRE. In addition, studies that assess synergy between plazomicin and other antibiotics are recommended.

Furthermore, clinical trial studies are recommended to evaluate the efficacy of plazomicin in the treatment of infections caused by CRE.

\section{References}

1. Harting J. Carbapenem-resistant Enterobacteriaceae infections: A review of epidemiology and treatment options. Univ Louisville J Respir Infect. 2019;3(1):4.

2. Temkin E, Adler A, Lerner A, Carmeli Y. Carbapenem-resistant Enterobacteriaceae: Biology, epidemiology, and management. Ann N Y Acad Sci. 2014;1323(1):22-42. https://doi.org/10.1111/ nyas. 12537

PMid:25195939

3. Centers for Disease Control and Prevention. Facility Guidance for Control of Carbapenem-resistant Enterobacteriaceae (CRE)November 2015 Update CRE Toolkit. Atlanta, GA: United States Department of Health and Human Services; 2015.

4. Nordmann P, Naas T, Poirel L. Global spread of carbapenemase-producing Enterobacteriaceae. Emerg Infect Dis. 2011;17(10):1791. https://doi.org/10.3201/eid1710.110655 PMid:22000347

5. Schwaber MJ, Carmeli Y. Carbapenem-resistant Enterobacteriaceae: A potential threat. JAMA. 2008;300(24):2911-3. https://doi.org/10.1001/jama.2008.896 PMid: 19109119

6. Kelly AM, Mathema B, Larson EL. Carbapenem-resistant Enterobacteriaceae in the community: A scoping review. Int $\mathrm{J}$ Antimicrob Agents. 2017;50(2):127-34. https://doi.org/10.1016/j. ijantimicag.2017.03.012

PMid:28647532

7. Nasiri MJ, Mirsaeidi M, Mousavi SM, Arshadi M, Fardsanei F, Deihim B, et al. Prevalence and mechanisms of carbapenem resistance in Klebsiella pneumoniae and Escherichia coli: A systematic review and meta-analysis of cross-sectional studies from Iran. Microbial Drug Resist. 2020;26(12):1491-502. https://doi.org/10.1089/mdr.2019.0440

PMid:32348701

8. Kotb S, Lyman M, Ismail G, Abd El Fattah M, Girgis SA, Etman A et al. Epidemiology of carbapenem-resistant Enterobacteriaceae in Egyptian intensive care units using national healthcareassociated infections surveillance data, 2011-2017. Antimicrob Resist Infect Control. 2020;9(1):1-9. https://doi.org/10.1186/ s13756-019-0639-7

PMid:31911830
9. Elshamy AA, Aboshanab KM. A review on bacterial resistance to carbapenems: Epidemiology, detection and treatment options. Future Sci OA. 2020;6(3):FSO438. https://doi.org/10.2144/ fsoa-2019-0098

PMid:32140243

10. Castanheira M, Deshpande LM, Woosley LN, Serio AW, Krause KM, Flamm RK. Activity of plazomicin compared with other aminoglycosides against isolates from European and adjacent countries, including Enterobacteriaceae molecularly characterized for aminoglycoside-modifying enzymes and other resistance mechanisms. J Antimicrob Chemother. 2018;73(12):3346-54. https://doi.org/10.1093/jac/dky344 PMid:30219857

11. Walkty A, Karlowsky JA, Baxter MR, Adam HJ, Zhanel GG. In vitro activity of plazomicin against gram-negative and gram-positive bacterial pathogens isolated from patients in Canadian hospitals from 2013 to 2017 as part of the CANWARD surveillance study. Antimicrob Agents Chemother. 2019;63(1):e02068-18. https:// doi.org/10.1128/AAC.02068-18 PMid:30373806

12. US Food. Drug Administration Antimicrobial Drugs Advisory Committee. FDA Briefing Document: Plazomicin Sulfate Injection (NDA 210303). United States: US Food; 2018.

13. Mok WW, Brynildsen MP. Resistance and tolerance to aminoglycosides. In: Bacterial Resistance to Antibiotics-From Molecules to Man. United States: John Wiley and Sons, Inc.; 2019. p. 81-100.

14. Clinical and Laboratory Standards Institute. Performance Standards for Antimicrobial Susceptibility Testing. $29^{\text {th }}$ ed. Wayne, PA: Clinical and Laboratory Standards Institute; 2019.

15. Clinical and Laboratory Standards Institute. Performance Standards for Antimicrobial Susceptibility Testing. $30^{\text {th }}$ ed. Wayne, PA: Clinical and Laboratory Standards Institute; 2020.

16. Poirel L, Walsh TR, Cuvillier V, Nordmann P. Multiplex PCR for detection of acquired carbapenemase genes. Diagn Microbiol Infect Dis. 2011;70(1):119-23. https://doi.org/10.1016/j. diagmicrobio.2010.12.002 PMid:21398074

17. Andrei S, Droc G, Stefan G. FDA approved antibacteria drugs: 2018-2019. Discoveries. 2019;7(4):e102. https://doi. org/10.15190/d.2019.15 PMid:32309620

18. Tawfick MM, Alshareef WA, Bendary HA, Elmahalawy $H$, Abdulall AK. The emergence of carbapenemase bla NDM genotype among carbapenem-resistant Enterobacteriaceae isolates from Egyptian cancer patients. Eur J Clin Microbiol Infect Dis. 2020;39(7):1251-9. https://doi.org/10.1007/ s10096-020-03839-2

\section{PMid:32062725}

19. Grundmann H, Glasner C, Albiger B, Aanensen DM Tomlinson CT, Andrasević AT, et al. Occurrence of carbapenemase-producing Klebsiella pneumoniae and Escherichia coli in the European survey of carbapenemaseproducing Enterobacteriaceae (EuSCAPE): A prospective, multinational study. Lancet Infect Dis. 2017;17(2):153-63. https://doi.org/10.1016/S1473-3099(16)30257-2

PMid:27866944

20. Raheel A, Azab H, Hessam W, Abbadi S, Ezzat A. Detection of carbapenemase enzymes and genes among carbapenemresistant Enterobacteriaceae isolates in Suez Canal university hospitals in Ismailia, Egypt. Microbes Infect Dis. 2020;1(1):24-33.

21. Gelmez GA, Can B, Hasdemir U, Soyletir G. Evaluation of phenotypic tests for detection of carbapenemases: New modifications with new interpretation. J Infect Chemother. 2021;27(2):226-31. https://doi.org/10.1016/j.jiac.2020.09.021 PMid:33008736 
22. Ghaith DM, Zafer MM, Said HM, Elanwary S, Elsaban S, Al-Agamy $\mathrm{MH}$, et al. Genetic diversity of carbapenem-resistant Klebsiella Pneumoniae causing neonatal sepsis in intensive care unit, Cairo, Egypt. Eur J Clin Microbiol Infect Dis. 2020;39(3):58391. https://doi.org/10.1007/s10096-019-03761-2

PMid:31773363

23. Fleischmann WA, Greenwood-Quaintance KE, Patel R. In vitro activity of plazomicin compared to amikacin, gentamicin, and tobramycin against multidrug-resistant aerobic Gram-Negative Bacilli. Antimicrob Agents Chemother. 2020;64(2):e01711-19. https://doi.org/10.1128/AAC.01711-19

PMid:31712206

24. Castanheira M, Davis AP, Mendes RE, Serio AW, Krause KM Flamm RK. In vitro activity of plazomicin against Gramnegative and Gram-positive isolates collected from US hospitals and comparative activities of aminoglycosides against carbapenem-resistant Enterobacteriaceae and isolates carrying carbapenemase genes. Antimicrob Agents Chemother. 2018;62(8):e00313-8. https://doi.org/10.1128/AAC.00313-18 PMid:29866862

25. Clark JA, Kulengowski B, Burgess DS. In vitro activity of plazomicin compared to other clinically relevant aminoglycosides in carbapenem-resistant Enterobacteriaceae. Diagn Microbiol Infect Dis. 2020;98(2):115117. https://doi.org/10.1016/j. diagmicrobio.2020.115117

PMid:32755805

26. Jacobs MR, Good CE, Hujer AM, Abdelhamed AM, Rhoads DD, Hujer KM, et al. ARGONAUT II study of the in vitro activity of plazomicin against carbapenemase-producing Klebsiella pneumoniae. Antimicrob Agents Chemother. 2020;64(5):e00012-20. https://doi.org/10.1128/AAC.00012-20 PMid:32152078

27. Eljaaly K, Alharbi A, Alshehri S, Ortwine JK, Pogue JM. Plazomicin: A novel aminoglycoside for the treatment of resistant Gram-negative bacterial infections. Drugs. 2019;79(3):243-69. https://doi.org/10.1007/s40265-019-1054-3

PMid:30723876

28. Zhang $\mathrm{Y}$, Kashikar A, Bush K. In vitro activity of plazomicin against $\quad \beta$-lactamase-producing carbapenem-resistant Enterobacteriaceae (CRE). J Antimicrob Chemother. 2017;72(10):2792-5. https://doi.org/10.1093/jac/dkx261

PMid:29091224 